\title{
ANALISIS BIAYA DAN PENDAPATAN USAHATANI PADI DI KABUPATEN KARANGANYAR
}

\section{COST AND REVENUE ANALYSIS OF RICE FARMING IN KARANGANYAR REGENCY}

\author{
Umi Barokah, Wiwit Rahayu, dan Mei Tri Sundari *)
}

Diterima 27 Oktober 2014, disetujui 10 Nopember 2014

\begin{abstract}
Rice is the food crop with the harvested area and production of the highest among other food crops in Karanganyar Regency. From year to year, its harvested area, production, and productivity tend to increase. These increments showed that rice farming is still in demand by farmers. This study aims to analyze the cost, revenue, and efficiency of rice farming in this regency. The study was conducted in 4 districts; Gondangrejo, Karanganyar, Jaten, and Jatipura. From each district were taken two villages. In total, there were 159 farm households sampled randomly. In average, the revenue of rice farming in Karanganyar is Rp14,429,117.37/ha/year with yearly costs of $R p 7,142,446.39 / h a$. The average annual income therefore reaches $R p 7,286,670.98 / h a$. The value of rice farming efficiency is 2.02 indicating that rice farming in Karanganyar is worth the effort.
\end{abstract}

Keywords: rice farming, efficiency, Karanganyar Regency

\section{PENDAHULUAN}

Usahatani adalah suatu kegiatan mengusahakan dan mengkoordinir faktor-faktor produksi berupa lahan, tenaga kerja, dan modal sehingga memberikan manfaat sebaik-baiknya. Usahatani merupakan cara-cara menentukan, mengorganisasikan, dan mengkoordinasi penggunaan factorfaktor produksi seefektif dan seefisien mungkin sehingga usaha tersebut memberikan pendapatan semaksimal mungkin (Suratiyah, 2008).

Usaha di sektor petanian dibedakan menjadi 5 sub sektor yaitu sub sektor tanaman bahan pangan, perkebunan, kehutanan, perikanan, dan peternakan. Salah satu komoditas yang dihasilkan oleh sub sektor tanaman bahan makanan adalah padi yang merupakan sumber pangan pokok sebagian besar masyarakat Indonesia termasuk masyarakat Kabupaten Karanganyar. Di Kabupaten Karanganyar, padi merupakan tanaman pangan utama yang ditanam oleh petani.

Dari tahun ke tahun, luas panen, produksi dan produktivitas padi di Kabupaten Karanganyar cenderung meningkat. Perkembangan luas areal panen, produksi dan produktivitas padi di Kabupaten Karanganyar tahun 2005-2010 disajikan pada Tabel 1.

Peningkatan luas areal panen dan produksi padi menunjukkan bahwa usahatani padi masih diminati oleh petani di Kabupaten Karanganyar. Bagi petani padi, usahatani padi berperan dalam menyediakan pangan pokok dan sumber pendapatan rumah tangga. Suratiyah (2008) menge-

${ }^{*}$ Program Studi Agribisnis, Fakultas Pertanian Universitas Sebelas Maret Surakarta email:har_umi10@yahoo.com,wiwit_uns@yahoo.com,meitrisundari@gmail.com 
mukakan bahwa tujuan akhir usahatani keluarga adalah pendapatan keluarga petani yang terdiri atas laba, upah tenaga kerja keluarga, dan bunga modal sendiri. Pendapatan yang dimaksud adalah selisih antara nilai produksi dikurangi dengan biaya yang dikeluarkan oleh petani.

Hasil penelitian Antriyandarti dkk (2012) menunjukkan bahwa usahatani komoditas padi di Kabupaten Grobogan tidak menguntungkan secara privat maupun sosial. Nilai R/C yang rasio kurang dari satu menunjukkan bahwa usahatani padi tidak efisien. Di sisi lain penelitian Jannah (2014) menunjukkan bahwa usahatani padi sawah di Kecamatan Karanganyar Kabupaten Karanganyar memberikan kontribusi terhadap pendapatan total rumah tangga petani padi sebesar 65,47 persen. Ini menunjukkan usahatani padi di Kecamatan Karanganyar memiliki peran yang besar dalam memberikan pendapatan kepada rumah tangga petani.

Berdasarkan latar belakang tersebut di atas, penelitian ini bertujuan untuk menganalisis biaya, pendapatan, dan efisiensi usahatani padi di Kabupaten Karanganyar.

\section{METODE PENELITIAN}

Metode dasar yang digunakan dalam penelitian ini adalah deskriptif analitis (Narbuko dan Ahmadi, 2004).Teknik yang digunakan dalam penelitian ini adalah teknik survei yang dilaksanakan dengan mengambil sampel dari satu populasi dengan menggunakan kuisioner sebagai alat pengumpul data (Singarimbun dan Effendi, 1995).

Penelitian dilakukan di 4 kecamatan, di Kabupaten Karanganyar yaitu Kecamatan Gondangrejo, Jaten, Jatipura, dan Karanganyar. Dari masingmasing kecamatan diambil 2 desa. Jumlah sampel sebanyak 159 rumah tangga petani padi yang diambil secara acak sederhana dengan didasarkan pada kerangka sampel Rencana Definitif Kebutuhan Kelompok (RDKK) dari masing-masing desa.

Data yang digunakan meliputi data primer dan sekunder. Data primer diperoleh melalui hasil wawancara dan observasi langsung. Data sekunder yang digunakan diperoleh dari instansi terkait di Kabupaten Karanganyar (BPS; Dinas Pertanian, Perkebunan dan Kehutanan; Dinas Sosial, Tenaga Kerja dan Transmigrasi serta empat kecamatan yang dijadikan sebagai lokasi penelitian.

Pada penelitian ini analisis biaya dilakukan dengan menghitung biaya yang benar-benar dikeluarkan dalam usahatani padi.Penerimaan usaha tani padi dihitung dengan rumus:

Penerimaan $=$ Py. Y

Di mana Py: Harga produksi $(\mathrm{Rp} / \mathrm{Kg})$ dan

$\mathrm{Y}$ : Jumlah produksi $(\mathrm{Kg})$

(Suratiyah, 2008)

Tabel 1. Perkembangan Luas Areal Panen, Produksi dan Produktivitas Padi di Kabupaten Karanganyar Tahun 2005-2010

\begin{tabular}{cccc}
\hline Tahun & $\begin{array}{c}\text { Luas Areal Panen } \\
(\mathrm{Ha})\end{array}$ & $\begin{array}{c}\text { Produksi GKG }(\mathrm{Kw}) \\
\text { (Ton) }\end{array}$ & $\begin{array}{c}\text { Produktivitas } \\
\text { (Ton/Ha) }\end{array}$ \\
\hline 2005 & 40.279 & 213.841 .211 & 5,31 \\
2006 & 42.402 & 236.051 .934 & 5,57 \\
2007 & 42.826 & 243.679 .940 & 5,69 \\
2008 & 46.458 & 274.566 .780 & 5,91 \\
2009 & 47.545 & 281.751 .670 & 5,93 \\
2010 & 49.332 & 295.646 .676 & 5,99 \\
\hline
\end{tabular}

Sumber : Deptan (2012) 
Pendapatan usahatani padi adalah selisih antara penerimaan dan semua biaya usahatani padi. Pendapatan usahatani padi dihitung dengan rumus:

$\mathrm{Pd}=\mathrm{TR}-\mathrm{TC}$

Di mana Pd : Pendapatan usahatani padi,

TR: Total penerimaan usahatani padi, dan

TC: Total biaya usahatani padi (Soekartawi, 2006).

Sedangkan efisiensi usahatani padi dihitung dengan rumus:

Efisiensi= R/C

Dimana $R$ : total penerimaan usahatani padi dan $\mathrm{C}$ : total biaya usahatani padi.

\section{HASIL DAN PEMBAHASAN}

\section{Karakteristik Rumah Tangga Petani Padi}

Karakteristik rumah tangga petani merupakan gambaran umum mengenai keadaan rumah tangga petani padi. Karakteristik rumah tangga petani yang dikaji dalam penelitian ini meliputi umur, pendidikan, jumlah anggota rumah tangga, jumlah anggota rumah tangga yang aktif dalam usahatani, dan pengalaman berusahatani padi. Karakteristik rumah tangga petani disajikan pada Tabel 2.

Tabel 2. menunjukkan bahwa petani padi ratarata berumur 57 tahun dan isterinya berumur 47 tahun. Umur petani padi berkisar antara 31 tahun sampai 80 tahun dengan jumlah petani berumur di atas 65 tahun sebanyak 36 orang atau 22,93 persen. Sedangkan umur isteri berkisar antara 27 tahun sampai 75 tahun. Suami sebagai pelaku utama aktivitas usahatani rata-rata umurnya masih tergolong produktif tetapi 22,93 persennya tergolong usia tidak produktif. Hal ini menunjukkan bahwa pada usahatani padi didominasi oleh petani berusia tua. Oleh karena itu petani menggunakan bantuan mesin pertanian seperti bajak dalam usahatani padi. Petani menggunakan mesin dengan alasan tenaga tidak mencukupi kalau diolah dengan tenaga sendiri karena ada petani yang berusia di atas 65 tahun. Selain itu penggu-

Tabel 2. Karakteristik Rumah Tangga Petani Padi di Kabupaten Karanganyar

\begin{tabular}{clr}
\hline No. & \multicolumn{1}{c}{ Karakreristik } & Jumlah \\
\hline 1. & Rata-rata umur (tahun) & 57 \\
& a. Suami & 47 \\
b. Isteri & \\
2. Pendidikan (orang) & 43 \\
& Suami: & 62 \\
a. Tidak tamat SD & 28 \\
b. SD & 20 \\
c. SMP & 4 \\
d. SMA & 67 \\
e. D2/D3/Sarjana & \\
c. Pendidikan non formal & 38 \\
Isteri: & 70 \\
a. Tidak tamat SD & 22 \\
b. SD & 14 \\
c. SMP & 5 \\
d. SMA & 3 \\
e. D2/D3Sarjana & 33 \\
Rata-rata jumlah anggota rumah tangga (orang) & 2 \\
Penglaman Usahatani (tahun) & \\
5. Rata-rata jumlah anggota rumah tangga yang aktif dalam usahatani padi (orang) & \\
&
\end{tabular}

Sumber : Analisis Data Primer (2013) 
naan mesin pertanian dilakukan dengan alasan pekerjaan lebih cepat selesai dan biaya lebih ringan.

Pendidikan petani padi maupun isterinya sebagian besar tidak tamat SD dan tamat SD. Hal ini menunjukkan pendidikan petani padi sebagian besar tergolong rendah. Petani padi tetap dapat berusahatani meskipun pendidikan formalnya rendah karena petani sudah lama berkecimpung dalam pertanian padi. Sebagian besar petani telah aktif dalam usahatani padi sejak kecil dan rata-rata berpengalaman lebih dari 33 tahun. Selain itu, sebanyak 67 petani pernah memperoleh pendidikan nonformal dari berbagai kegiatan seperti penyuluhan dan pelatihan. Dengan adanya pendidikan non formal ini pengetahuan petani akan lebih maju sehingga dapat menunjang kemajuan usahataninya meskipun pendidikan formalnya rendah.

Rata-rata jumlah anggota rumah tangga petani padi adalah 3 orang dan rata-rata jumlah anggota keluarga yang aktif dalam usahatani sebanyak 2 orang. Anggota keluarga yang aktif dalam usahatani adalah suami dan isteri atau suami dan anak. Anak-anak yang tidak aktif dalam usahatani padi dikarenakan masih sekolah atau sudah bekerja di bidang lain.

\section{Biaya, Pendapatan, dan Efisiensi Usahatani Padi}

1. Biaya usahatani padi

Biaya usahatani dihitung berdasarkan jumlah nilai uang yang benar-benar dikeluarkan oleh petani untuk membiayai kegiatan usahataninya yang meliputi biaya sarana produksi, biaya tenaga kerja dan biaya lain-lain. Biaya sarana produksi usahatani padi di Kabupaten Karanganyar disajikan pada Tabel 3 .

Dari Tabel 3 diketahui rata-rata biaya sarana produksi pada usahatani padi adalah sebesar Rp 2.346.459,18/Ha/Th dengan pengeluaran saprodi terbesar adalah pada penggunaan pupuk

Tabel 3. Rata-rata Biaya Sarana Produksi pada Usahatani Padi di Kabupaten Karanganyar

\begin{tabular}{rlrrr}
\hline \multirow{2}{*}{ No. } & Uraian & \multicolumn{1}{c}{$\begin{array}{c}\text { Biaya } \\
\text { Per Usahatani (Rp) }\end{array}$} & $\begin{array}{c}\text { Biaya } \\
\text { Per Hektar (Rp) }\end{array}$ & \multicolumn{1}{c}{$\%$} \\
\hline 1 & Benih & $594.446,17$ & $400.453,00$ & 17,07 \\
2 & Pupuk & & & \\
& Kandang & $7.987,04$ & $5.380,53$ & 0,23 \\
& Organik & $109.891,83$ & $74.029,43$ & 3,15 \\
& Urea & $641.024,43$ & $431.830,79$ & 18,40 \\
& Za & $379.087,36$ & $255.374,97$ & 10,88 \\
& SP36 & $425.883,65$ & $286.899,63$ & 12,23 \\
& KCl & $21.702,55$ & $14.620,08$ & 0,62 \\
& Ponska & $698.581,22$ & $470.604,34$ & 20,06 \\
3 & Pestisida & & & \\
& Furadan & $77.243,77$ & $52.035,83$ & 2,22 \\
& Score & $105.094,88$ & $70.797,94$ & 3,02 \\
& Arifo & $22.600,63$ & $15.225,08$ & 0,65 \\
& Round up & $3.635,61$ & $2.449,16$ & 0,10 \\
& Regen & $21.295,05$ & $14.345,56$ & 0,61 \\
& Lain-lain & $223.911,45$ & $150.839,58$ & 6,43 \\
4 & Lain-lain & $150.778,83$ & $101.573,26$ & 4,33 \\
\hline & Jumlah & $3.483 .164,48$ & $2.346 .459,18$ & 100,00 \\
\hline
\end{tabular}

Sumber : Analisis Data Primer (2013) 
ponska yaitu sebesar Rp 470.604,34/Ha/Th, karena pupuk phonska diberikan sebagai pupuk dasar dan pupuk susulan sehingga pemakaiannya relatif lebih banyak dibandingkan dengan jenis pupuk yang lain, selain itu harga pupuk phonska di daerah petani mencapai Rp.115.000-125000 per sak dimana setiap sak berisi $50 \mathrm{~kg}$ pupuk phonska. Biaya terbesar yang kedua dan ketiga adalah biaya pembelian pupuk urea sebesar $431.830,79 / \mathrm{Ha} / \mathrm{Th}$ dan biaya pembelian benih sebesar $400.453,00 /$ $\mathrm{Ha} / \mathrm{Th}$.

Petani tidak banyak mengeluarkan biaya untuk pembelian pestisida, yaitu hanya sebesar Rp. 305.693,15 rupiah./Ha/Th. Biaya untuk pembelian pestisida ini merupakan biaya terkecil yang dikeluarkan petani, karena hama dan penyakit yang menyeranng tanaman tidak begitu banyak, selain itu petani cenderung mengguna-kan pastisida organik, ramuan petani sendiri dan mengurangi penggunaan pestisida kimia sehingga bisa menghemat biaya. Pestisida yang digunakan antara lain furadan, score, Arifo, round up, regen dan pestisida organik ramuan sendiri.

Komponen biaya yang kedua adalah biaya tenaga kerja. Rata-rata biaya penggunaan tenaga kerja pada usahatani padi dapat dilihat pada Tabel 4.
Tabel 4 menunjukkan bahwa total biaya tenaga kerja yang digunakan dalam usahatani padi adalah sebesar Rp 4.043.556,65/Ha/Th dengan biaya terbesar adalah untuk penanaman $(\operatorname{Rp} 936.289,51$ $/ \mathrm{Ha} / \mathrm{Th}$ ) dan biaya terkecil adalah untuk kegiatan persemaian (Rp 11.876,99/Ha/Th). Upah untuk tenaga kerja harian berkisar antara Rp 40.000 Rp 50.000 per hari. Perhitungan biaya tenaga kerja adalah biaya yang benar-benar dikeluarkan yaitu upah tenaga kerja luar. Biaya persemaian merupakan biaya terkecil karena tenaga kerja yang digunakan sebagian besar adalah tenaga kerja dalam. Sedangkan biaya penanaman merupakan biaya terbesar karena tenaga kerja penanaman sebagian besar merupakan tenaga kerja luar keluarga.

Komponen biaya yang terakhir adalah biaya lainlain, meliputi meliputi biaya pengairan, selamatan, cicilan pinjaman dan pajak sawah. Uraian mengenai rata-rata biaya lain-lain, dapat dilihat pada Tabel 5.

Biaya lain-lain yang dikeluarkan oleh petani adalah sebesar Rp 752.430,56/Ha/Th. Biaya lain-lain ini terdiri atas pengairan (Rp 394.405,49/Ha/Th), selamatan (Rp 18.622,66/Ha/Th), cicilan pinjaman

Tabel 4. Rata-rata Biaya Tenaga Kerja pada Usahatani Padi di Kabupaten Karanganyar

\begin{tabular}{|c|c|c|c|c|}
\hline \multirow{2}{*}{ No } & \multirow{2}{*}{ Keterangan } & \multicolumn{2}{|c|}{ Biaya } & \multirow{2}{*}{$\%$} \\
\hline & & per UT & Per Ha & \\
\hline 1 & Persemaian & $17.547,17$ & $11.876,99$ & 0,29 \\
\hline 2 & Mencangkul & $862.169,81$ & $583.568,61$ & 14,43 \\
\hline 3 & Membajak & $1.106 .899,37$ & $749.216,36$ & 18,53 \\
\hline 4 & Penanaman & $1.383 .283,02$ & $936.289,51$ & 23,16 \\
\hline 5 & Penyiangan & $695.764,15$ & $470.935,21$ & 11,65 \\
\hline 6 & Pengairan & $560.540,88$ & $379.407,93$ & 9,38 \\
\hline 7 & Pemberantasan hama & $81.194,97$ & $54.957,66$ & 1,36 \\
\hline 8 & Pemanenan & $43.238,99$ & $29.266,76$ & 0,72 \\
\hline \multirow[t]{2}{*}{9} & Angkut hasil & $1.223 .350,63$ & $828.037,61$ & 20,48 \\
\hline & Jumlah & $5.973 .988,99$ & $4.043 .556,65$ & 100,00 \\
\hline
\end{tabular}

Sumber : Analisis Data Primer (2013) 
(Rp 231.489,46/Ha/Th) dan pajak sawah (Rp 107.912,95/Ha/Th).

Biaya pengairan merupakan biaya bensin yang dikeluarkan petani sebagai bahan bakar pompa diesel untuk pengairan, dimana tiap liter bensin dihitung dengan harga $\mathrm{Rp} 6.000,00$ dan biaya pengairan dihitung sesuai dengan kuantitas pengairan yang dilakukan petani. Biaya pengairan ini merupakan biaya yang tertinggi dalam komponen biaya lain-lain.
Penerimaan Usahatani Padi

Penerimaan usahatani dalam penelitian ini dihitung dengan mengalikan besarnya produksi padi dengan harga jual padi per kilogram. Rata-rata penerimaan usahatani padi di Kabupaten Karanganyar dapat dilihat pada Tabel 7 .

Produksi rata-rata padi yang diperoleh petani adalah sebanyak $2.323,75 \mathrm{Kg} / \mathrm{Ha}$ dengan harga padi ratarata setiap kilogramnya Rp 6.209,41, sehingga

Tabel 5. Rata-rata Biaya Lain-lain pada Usahatani Padi di Kabupaten Karanganyar

\begin{tabular}{clrrr}
\hline No. & Macam biaya & $\begin{array}{c}\text { Per Usahatani } \\
(\mathrm{Rp})\end{array}$ & $\begin{array}{c}\text { Per hektar } \\
(\mathrm{Rp})\end{array}$ & \multicolumn{1}{c}{$\%$} \\
\hline 1 & Pengairan & $583.720,12$ & $394.405,49$ & 52,41 \\
2 & Selamatan & $27.561,54$ & $18.622,66$ & 2,47 \\
3 & Cicilan Pinjaman & $342.604,40$ & $231.489,46$ & 30,76 \\
4 & Pajak Sawah & $212.947,73$ & $107.912,95$ & 1,34 \\
\hline Jumlah & & $1.166 .833,79$ & $752.430,56$ & 100,00
\end{tabular}

Sumber: Analisis Data Primer 2013

Berdasarkan uraian biaya di atas, biaya total yang dikeluarkan petani dalam usahatani padi meliputi biaya saprodi, biaya tenaga kerja, dan biaya lainlain. Rata-rata biaya total usahatani padi di Kabupaten karanganyar disajikan pada Tabel 6.

Tabel 6. menunjukkan bahwa biaya total yang dikeluarkan petani untuk usahatani padi sebesar Rp 7.142.446,39/Ha/Th. Biaya tersebut terdiri atas biaya saprodi (Rp 2.346.459,18Ha/Th), biaya tenaga kerja (Rp 4.043.556,65/Ha/Th) dan biaya lain-lain sebesar Rp 752.430,56/Ha/Th. Pengeluaran biaya paling besar adalah untuk biaya tenaga kerja $(56,61 \%)$. diperoleh penerimaan petani pada usaha tani padi sebesar Rp 14.429.116,49/Ha/Th.

\section{Pendapatan dan Efisiensi Usahatani Padi}

Pendapatan usahatani padi dihitung dengan mengurangkan penerimaan dengan biaya usaha-tani padi.Sedangkan efisiensi merupakan per-bandingan antara penerimaan dengan total biaya yang dikeluarkan dalam usahatani padi. Rata-rata pendapatan dan efisiensi usahatani padi di Kabupaten Karanganayar dapat dilihat pada Tabel 8 .

Tabel 6. Biaya Total Usahatani Padi di Kabupaten Karanganyar

\begin{tabular}{llrrr}
\hline No. & \multicolumn{1}{c}{ Macam biaya } & $\begin{array}{c}\text { Per Usahatani } \\
(\mathrm{Rp})\end{array}$ & \multicolumn{1}{c}{$\begin{array}{c}\text { Per hektar } \\
(\mathrm{Rp})\end{array}$} & \multicolumn{1}{c}{$\%$} \\
\hline 1 & Biaya Saprodi & $3.483 .164,48$ & $2.346 .459,18$ & 32,85 \\
2 & Biaya Tenaga Kerja & $5.973 .988,99$ & $4.043 .556,65$ & 56,61 \\
3 & Biaya Lain-lain & $1.166 .833,79$ & $752.430,56$ & 10,53 \\
\hline Jumlah & $10.623 .987,26$ & $7.142 .446,39$ & 100,00 \\
\hline
\end{tabular}

Sumber: Analisis Data Primer 2013 
Tabel 7. Rata-rata Penerimaan Usahatani Padi di Kabupaten Karanganyar

\begin{tabular}{llrr}
\hline No. & Keterangan & Per Usahatani & \multicolumn{1}{c}{ Per hektar } \\
\hline 1. & Produksi $(\mathrm{Kg})$ & $3.449,45$ & $2.323,75$ \\
2. & Harga Produksi $(\mathrm{Rp} / \mathrm{Kg})$ & $6.209,41$ & $6.209,41$ \\
3. & Penerimaan $(\mathrm{Rp})$ & $21.419 .049,32$ & $14.429 .116,49$
\end{tabular}

Sumber : Analisis Data Primer (2013)

Tabel 8. Rata-rata Pendapatan dan Efisiensi Usahatani Padi di Kabupaten Karanganyar

\begin{tabular}{llrr}
\hline No. & \multicolumn{1}{c}{ Uraian } & $\begin{array}{c}\text { Per usahatani } \\
(\mathrm{Rp})\end{array}$ & \multicolumn{1}{c}{$\begin{array}{c}\text { Per hektar } \\
(\mathrm{Rp})\end{array}$} \\
\hline 1. & Penerimaan usahatani & $21.419 .049,32$ & $14.429 .117,37$ \\
2. & Biaya usahatani & $10.623 .987,26$ & $7.142 .446,39$ \\
3. & Pendapatan usahatani & $10.795 .062,06$ & $7.286 .670,98$ \\
4. & Efisiensi (R/C) & 2,02 & 2,02 \\
\hline
\end{tabular}

Sumber : Analisis Data Primer (2013)

Berdasarkan Tabel 8. dapat diketahui bahwa ratarata penerimaan usahatani padi sebesar $\mathrm{Rp}$ 14.429.117,37/Ha/Th dengan biaya usahatani sebesar Rp 7.142.446,39/Ha/Th, sehingga diperoleh rata-rata pendapatan usahatani padi sebesar Rp 7.286.670,98/Ha/Th.

Efisiensi usahatani padi ditunjukkan dengan nilai $\mathrm{R} / \mathrm{C}$ rasio sebesar 2,02 yang berarti setiap 1 rupiah biaya yang dikeluarkan dalam usahatani padi akan diperoleh penerimaan sesesar 2.02 rupiah. Nilai R/C rasio yang lebih dari satu menunjukkan bahwa usahatani padi di Kabupaten layak untuk diusahakan dan dikembangkan.

\section{KESIMPULAN DAN SARAN}

\section{Kesimpulan}

1. Rata-rata penerimaan usahatani padi di Kabupaten Karanganyar sebesar Rp 14.429.117,37/ $\mathrm{Ha} / \mathrm{Th}$ dan biaya usahatani sebesar $\mathrm{Rp}$ 7.142.446,39/Ha/Th, sehingga diperoleh ratarata pendapatan usahatani padi sebesar Rp 7.286.670,98/Ha/Th.

2. Nilai efisiensi usahatani padi sebesar 2,02 menunjukkan bahwa usahatani padi di Kabupaten karanganyar layak untuk diusahakan.

\section{Saran}

Biaya tenaga kerja merupakan komponen biaya terbesar dalam usahatani padi di Kabupaten Karanganyar. Petani dengan dukungan pemerintah sebaiknya meningkatkan efisiensi usahatani padi untuk meningkatkan pendapatan yaitu dengan menggunakan teknologi khususnya teknologi penanaman karena biaya tenaga kerja terbesar adalah biaya tenaga kerja untuk penanaman.

\section{DAFTAR PUSTAKA}

Anonim. 2012. Statistik Pertanian 2012. Pusat Data dan Sistem Informasi Pertanian. Kementrian Pertanian. Jakarta.

Badan Pusat Statistik. 2012. Kabupaten Karanganyar dalam Angka 2012. BPS, Karanganyar.

Antriyandarti, E., S. W. Ani, dan M. Ferichani. Analisis Privat dan Sosial Usahatani Padi di Kabupaten Grobogan. Jurnal SEPA. September 2012 Vol 9 (1): 12-18. 
Jannah, K. 2014. Kontribusi Usahatani Padi Terhadap Pendapatan dan Ketersediaan Energi Rumah Tangga Petani Padi di Kecamatan Karanganyar Kabupaten Karanganyar. Skripsi. Fakultas Pertanian, Universitas Sebelas Maret, Surakarta.

Narbuko, C. dan A. Achmadi. 2004. Metodologi Penelitian. Jakarta: PT Bumi Aksara.
Singarimbun, M. dan S. Effendi. 1995. Metode Penelitian Survey. Jakarta: LP3ES.

Soekartawi 2006. Analisis Usahatani. Jakarta: UI Press.

Suratiyah Ken 2008. Ilmu Usahatani. Jakarta: Penebar Swadaya. 